\title{
Population Trends and Fire Prevention in Merseyside UK
}

\author{
M. Taylor*, Department of Computer Science, Liverpool John Moores \\ University, Byrom Street, Liverpool L3 3AF, England \\ D. Appleton, G. Oakford and J. Fielding, Merseyside Fire and Rescue Service, \\ Bridle Road, Liverpool L30 4YD, England
}

Received: 28 April 2020/Accepted: 17 December 2020/Published online: 3 February 2021

\begin{abstract}
In this paper, we examine fire prevention planning in terms of analysis of population trends with regard to the area covered by Merseyside fire and rescue service in the North West of England. In particular, we present an examination of the potential impact of changing population characteristics previously identified as being associated with fire risk such as old age, living alone, behaviours and lifestyles such as smoking and alcohol consumption, and health and social care provision for the most vulnerable groups upon fire prevention strategies. Overall, the examination of the likely impact of population trends on fire risk identified the following impacts for the area covered for the fire and rescue service concerned: a likely increase in fire risk associated with the elderly and those with a long-term health problem or disability, and a likely decrease in fire risk associated with smoking and alcohol consumption, apart from alcohol consumption by the elderly. Based upon this analysis fire prevention for this area should increasingly target the elderly, the disabled and those with mental health and neurological conditions. This would be relevant to other fire and rescue services worldwide that have similar population trends that could impact fire risks, and also provide guidance for appropriate actions with regard to fire prevention.
\end{abstract}

Keywords: Fire, Prevention, Planning, Population, Trends

\section{Introduction}

Different population segments can have different levels and types of fire risk associated with them [38],[20]. Different population behaviours and lifestyles can also impact the level of fire risk [10],[37]. Over time, the makeup of an area in terms of the proportions of different population segments, and the nature of these population segments themselves may change. Thus, the fire risk factors within an area may change over time, potentially necessitating changes to the manner of fire prevention, in order for such to remain effective. Currently there does not appear to be widely used models available for assessing the potential impact of population changes upon fire risk, in order to inform potential changes required to fire pre-

\footnotetext{
*Correspondence should be addressed to: M. Taylor, E-mail: m.j.taylor@ljmu.ac.uk
} 
vention strategies. In this paper, we examine the potential impact of population changes upon fire risk. The risk of fire has been identified as being higher for the elderly and the disabled in numerous countries along with the increasing proportions of such individuals in the population [16], [12], [5], [22].

The research reported in this paper concerned the examination at a local level of the likely impact of population changes upon fire risk within an area, and its application in practice in Merseyside Fire and Rescue Service in the North West region of the UK. The originality of the research is an examination of the likely impact of population trends for population characteristics previously identified as being associated with fire risk, for use by fire and rescue services. The population trends examined included old age, living alone, behaviours and lifestyles such as smoking and alcohol consumption, and health and social care provision for the most vulnerable groups, previously identified as the major causal factors in unintentional dwelling fires [21], [10]. Other social factors such as income/wealth, education, and career were not included in the analysis since they are typically lesser causal factors in unintentional dwelling fires than factors such as old age, disability, and smoking and alcohol consumption [13], and data such as income/wealth, education, and career would typically not be included in fire incidence reporting within fire and rescue services.

A particular aspect of the trends in dwelling fire incidences and dwelling fire injuries was that the likelihood of a given fire incident involving a fire injury had increased slightly in the area studied by $6.5 \%$ from 2006 to 2016 [in 2006 there were 129 fire injuries out of 1384 fire incidences $(9.3 \%$ of fire incidences resulted in injury), in 2016 there were 104 fire injuries out of 1049 fire incidences $(9.9 \%$ of fire incidences resulted in injury)]. Overall, the analysis of population trends and their likely impact on fire prevention strategies is an important research topic in the context of typically reducing fire and rescue service budgets, and increasing populations within the UK and elsewhere. The research presented in this paper adds to the overall body of knowledge concerning fire prevention by presenting an examination of the potential impact of changing population characteristics upon fire prevention strategies. In the area in which the research was undertaken, population trends relating to previously identified main fire risk factors such as old age, living alone, behaviours and lifestyles such as smoking and alcohol consumption, and health and social care provision for the most vulnerable groups were examined. In different areas, different subsets of fire risk factors might have different relative risk levels associated with them which would determine their inclusion in the analysis, for example areas might have lower alcohol consumption rates, or lower proportions of elderly residents, making the approach presented more widely applicable. Since building codes and public regulations concerning fire risk are predominantly concerned with safety of life and evacuation in particular, there is a need to investigate if and how trends in population and life-style might impact upon this, especially as regards self-rescue and impairment. The approach presented in this paper concerns identifying what are the major causal factors in the area covered by a given fire and rescue service and then gathering and analysing relevant data connected with these causal factors in terms of population trends 
to determine the likely future impact in terms of fire risk and fire prevention strategies.

\section{Literature Review}

\subsection{Fire Prevention Planning}

Previous research had indicated that although factors such as poor housing stock, over-crowding, income/wealth, education, and careers can be associated with dwelling fire incidences, factors related to the individual such as age, smoking and alcohol consumption are far more relevant to fire prevention [21], [10]. Fire prevention planning involves understanding the current state of local communities [38], [36], historic population trends, and anticipation of likely future population trends [4].

\subsection{Population Segmentation and Fire Risk Assessment}

Community profiling via population segmentation [18], [38] can aid analytical work such as annual fire fatality reports. Previous research [13], [36], [7] had identified physical disability/long-term illness, age (particularly the elderly), living alone, smoking, alcohol intoxication, social deprivation, and smoke alarm not present as typically being the most significant causal factors in unintentional dwelling fires.

\subsection{Population Behaviours and Lifestyles and Fire Risk Assessment}

Different population behaviours and lifestyles such as smoking and alcohol consumption can have different levels of fire risk associated with them [10], [9]. Corcoran et al. [8] commented that lifestyle characteristics of localities can be used to analyse and understand fire risk levels and to identify the types of areas that are relatively more vulnerable to fire incidence than others.

\subsection{Vulnerable Groups and Fire Risk Assessment}

An increasingly vulnerable population in terms of fire risk associated with age and disability is a known issue in various parts of the world [22]. Approaches to enhance the identification of at-risk or vulnerable individuals are becoming ever more important to fire and rescue services. Vulnerability profiles can be used to indicate which individuals most require intervention from fire prevention services based on risk levels [18], [6]. Fernandez-Vigil and Trueba [12] stated that the onset of mental illness like dementia is a significant factor associated with fire risk for the elderly. The risk of developing dementia increases exponentially with age. With an increasingly ageing population in the UK and worldwide, the number of people with dementia is set to rise significantly in the decades to come [25]. 


\subsection{Population Trends and Fire Risk Assessment}

Various studies have indicated that population increases can affect fire risk levels [1], [24]. In particular, fire risk levels can increase in urban high population growth areas [45]. In many countries, increasingly ageing populations can present an increasing fire risk, since the elderly have been consistently identified as a high fire risk group [19], [44].

\subsection{Population Trends and Building Codes and Public Regulations Concerned with Fire Risk}

Miller [28] commented that building codes and standards such as the adoption of safer home heating technologies, with portable radiant heaters and open fires being replaced by heat pumps could assist in reducing domestic fire risk. In addition, the future use of sensors within the home, together with software to identify situations requiring intervention or assistance and notify relevant authorities could partially offset the increased fire risk associated with an aging population. The UK National Fire Chiefs Council [15] commented that building regulations should protect vulnerable individuals such as older people, and people with disabilities from the risk of dwelling fire.

\section{Research Method}

A case study involving merseyside fire and rescue service (MFRS) in the North West of the UK was undertaken concerning an examination of the potential impact of population trends upon fire risk levels, and the likely impacts upon fire prevention strategies. MFRS staff involved included the Fire Prevention Group Manager, Director of Strategy and Performance, Corporate Information and Systems Manager, and Business Intelligence Manager. The methodological challenges of assessing the impact of population trends included the availability of suitable data at a suitable level of geography and the timeframes of such data.

Based upon the literature review, and meetings with fire and rescue service staff, an examination of the impact of population trends on fire risk was undertaken. The first step concerned analysis of the different population segments within an area that can have different levels of fire risk [18], [38]. The second step concerned analysis of the different population behaviours and lifestyle such as smoking and alcohol consumption (which may be exhibited at different levels by different population segments) that can have different levels of fire risk associated with them [10]. The next step concerned analysis of the circumstances of the most vulnerable groups (including the elderly, the disabled, and those with long-term health conditions) that can affect the level of fire risk [18]. For the period 2006-2016 in Merseyside, $56 \%$ of fire fatality victims were over the age of $65,65 \%$ of fire fatality victims lived alone, and $52 \%$ of fire fatality victims had a disability. In addition, $51 \%$ of fire fatalities involved smoker's materials, and $40 \%$ of fire fatalities involved alcohol consumption. All of these fire risk factors were therefore deemed worthy of study in terms of the impact of population trends relating to these fac- 
tors, since these were the most significant fire risk factors for the population studied.

The next step concerned analysis of data from appropriate government statisti$\mathrm{cal}$, and healthcare agencies concerning predicted changes or historical trends relating to the size and composition of different population groups, their lifestyles and behaviours, and the circumstances of the most vulnerable groups. The final step concerned analysis of how the predicted changes or historical trends in population characteristics were likely to affect fire risk based upon historical and current levels of fire incidences associated with the different population characteristics. The steps in the approach are shown in the Annex.

The research questions posed were:

How can the potential impact of population trends on fire risk be assessed?

How can the potential impact of population behaviours and lifestyle trends on fire risk be assessed?

How can the potential impact of trends in the circumstances of vulnerable groups on fire risk be assessed?

How might trends in population and life-style impact fire safety building codes and public regulations concerned with safety of life and evacuation in particular (especially as regards self-rescue and impairment)?

These are important research questions since growing and changing populations, and continuing budget reductions necessitate a deeper understanding of the likely changes to fire risk associated with population changes, in order to be able to adapt to a changing fire risk landscape.

Data was sought regarding the current, historical, and projected values relating to population segments, population behaviours and lifestyles associated with fire risk, and the circumstances of the most vulnerable groups for the area concerned. The data obtained included:

- Dwelling fire data from MFRS over the period 2006-2016

- Population predictions for the areas covered by MFRS over the period 20142024, from the UK Office for National Statistics (ONS)

- The number of individuals living alone and the percentage of different age groups living alone, and the number of individuals with a long-term health problem or disability in Merseyside from the 2011 UK Census from the UK Office for National Statistics (ONS)

- The proportions of the UK population who smoked and the proportions of the UK population who drank more than the recommended maximum number of units of alcohol on their heaviest drinking day in the last week from 2006 to 2016 from UK NHS Statistics

- The percentages of the population of the North of England with mental health and neurological conditions in the period 2015-2016 from UK NHS Digital

A limitation of the research conducted was the availability of data. The only detailed projected data available for Merseyside was for population changes and 
dementia cases, although other projected data such as those living alone was available for the UK or England and Wales. Other data such as smoking and alcohol consumption levels was only available currently and historically, enabling historical trends to be analysed. Although finer-grained geographical area data would have been beneficial, such was simply not available.

The statistical methodology concerned comparing the population trends observed with dwelling fire data to determine the relationship between the population trends and fires associated with the relevant groups of individuals. However, given that data was only available on a yearly basis, there was insufficient recent data instances to be able to meet the required sample size for determining an actual correlation coefficient.

Sufficient population and fire incidence data was only available for some of the areas concerned. For example, fire incidence data did not include the age of those involved in the fire incidence, or whether they had a disability, this was only available for the much smaller numbers of fire injuries and fatalities.

\section{Results}

UK projected population trends are produced by the ONS [32]. UK population behaviours and lifestyles are regularly produced by the ONS [3], [35], from which trends can be established. Statistics regarding long-term health conditions such as dementia trends are available via NHS Statistics [11].

\subsection{Examination of the Impact of Population Trends on Fire Risk}

The first step concerned analysis of the different population segments within an area. Fire and rescue services may develop their own population segmentation models [38], or may use existing population segmentation models such as MOSAIC [29]. The next step concerned analysis of the different population segment behaviours and lifestyle such as smoking and alcohol consumption associated with fire risk [10]. The next step concerned analysis of the circumstances of the most vulnerable fire risk groups (including the elderly, disabled, and those with long-term health conditions) [18]. The next step concerned analysis of appropriate data from government statistical, and healthcare agencies concerning predicted changes or historical trends with regard to the size and composition of different population groups, their lifestyles and behaviours, and the circumstances of the most vulnerable groups. The final step concerned analysis of how the predicted changes or historical trends in population characteristics related to fire risk, in terms of the historical and current levels of fire incidences associated with the different population groups, lifestyles and behaviours and vulnerable groups.

- For different fire and rescue services, different subsets of fire risk factors might have different relative risk levels associated with them, for example some areas covered by fire and rescue services might have lower alcohol consumption rates, or lower proportions of elderly residents. 
- The approach presented in this paper concerns identifying what are the major causal factors in the area covered by a given fire and rescue service and then gathering and analysing relevant data connected with these causal factors in terms of population trends to determine the likely future impact in terms of fire risk and fire prevention strategies.

- In this manner the examination presented can be more widely applicable, since it provides a generic framework for determining what are the major population causal fire risk factors within an area, what data is available concerning the current and future state of such population characteristics, and how this can be analysed in terms of the relationships between the changes in the population characteristic over time, and the level of associated dwelling fire instances over time in order to inform future fire prevention strategies.

\subsection{Population Trends and Fire Risk}

The first step was to assess the proportions of different population segments within the area. Age is a key factor in the makeup of different population segments, as is living alone [40], and both had previously been identified as contributing to fire risk. In the period 2006-2016 in Merseyside, 56\% of fire fatality victims were aged 65 or over, and $65 \%$ of fire fatality victims lived alone.

The elderly are statistically one of the higher fire risk age groups [26]. The proportion of elderly individuals within the Merseyside region is projected to grow, thus indicating a potentially higher number and proportion of higher fire risk individuals within the region in the future. In Europe as a whole, in early 2018 there were 101.1 million older people (aged 65 years or more) living in the $28 \mathrm{EU}$ countries, equating to nearly a fifth $(19.7 \%)$ of the total population. During the next three decades, this figure is projected to rise up to 149.2 million inhabitants in 2050 ( $28.5 \%$ of the total population) [2].

In terms of the loss of life expectancy, since elderly people are more likely to die in a dwelling fire, there could be a significant loss of (years of) life expectancy for those involved in a dwelling fire. However, there are a very small number of fire deaths per year (on average 8 fire deaths per year in the time period studied) in Merseyside.

The predicted population increases in the areas covered by MFRS over the period 2014-2024 [32] were given for Fig. 1

The population of Liverpool in the 2011 UK Census was 552,267, Knowsley was 145,893 , Sefton was 273,790 , St. Helens was 102,885 , and Wirral was 319,783 . The predicted increases in those aged 65 and over (identified by MFRS as the most vulnerable age group in terms of fire risk) 2014-2024 [32] were given for Fig. 2

This indicated that the proportion of the population considered to be in a higher fire risk category (the elderly) is likely to increase significantly in the near future, posing a greater need for fire prevention activities. Over the period 20062016 the number of fire injuries in the Merseyside area declined from 129 to 100 per year, with the number aged 65 or over injured in a fire declining from 35 to 
Predicted population increases in Merseyside 2014 to 2024

$6.00 \%$

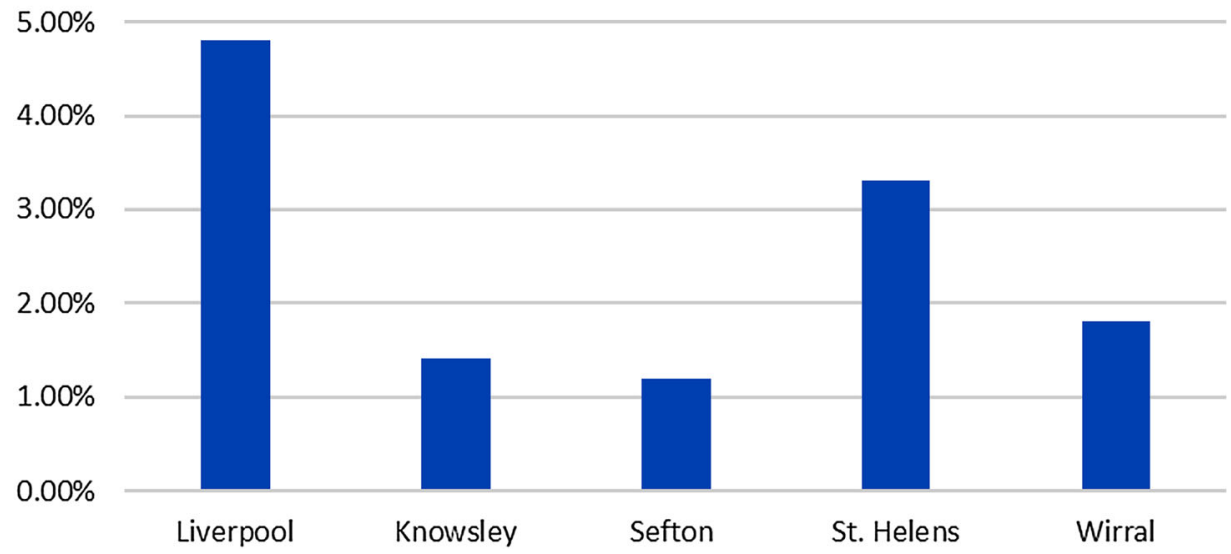

Figure 1. Predicted increases in overall population in MFRS area 2014-2024.

Predicted increases in 65+ age group in Merseyside 2014 to 2024

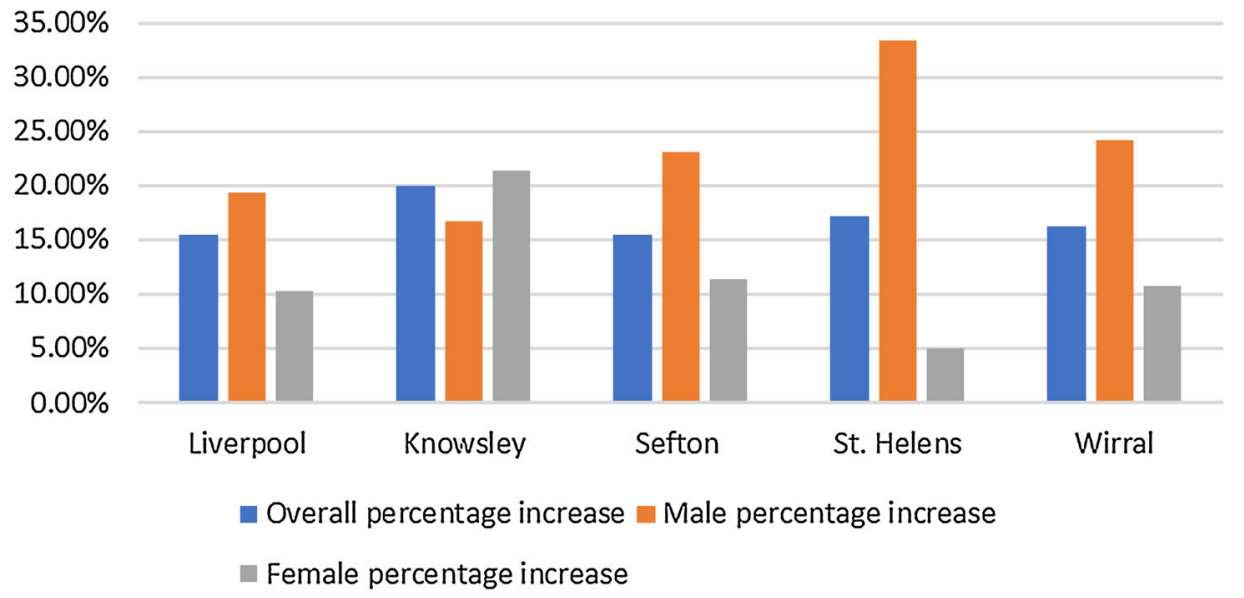

\section{Figure 2. Predicted percentage increases in those aged 65 and over} in MFRS area $2014-2024$.

25 , and number aged less than 65 injured in a fire declining from 94 to 75 . However, as a proportion of the elderly and non-elderly populations, the elderly still had a higher proportion of fire injuries throughout this period [39]. Unfortunately, the age of those involved in a fire incident is only recorded when there is an injury 
or fatality, and therefore it was not possible to compare fire incidences with the numbers or proportion of elderly residents over the time period concerned.

From the 2011 UK Census the number of individuals living alone (not in a couple) and the percentage of the given age group living alone (not in a couple) in Merseyside were [31] given for Fig. 3.

The number of people living on their own increased by $16 \%$ to 7.7 million between 1997 and 2017, whilst the UK population increased by only 13\% over this period. By 2039, the number of UK one-person households is projected to rise to 10.7 million. The rise in the number of people living alone is mainly concentrated in older age groups [33]. Given the projected increase in the percentage of $65+$ individuals living alone and that living alone is a known causal factor in unintentional dwelling fires, and that the $65+$ age group (already identified as a high fire risk group) is likely to increase in number significantly in the near future, fire prevention approaches would need to cater for this combined higher risk group of elderly and living alone individuals.

From the 2011 UK Census the number of individuals with a long-term health problem or disability in Merseyside was [31] given for Fig. 4:

Guzman-Castillo et al. [14] predicted a $25 \%$ increase in the number of those with a disability aged 65 or over in England and Wales over the period 20152025 .

- Given the projected increases in the number of individuals age 65 and over with a disability, it would appear that there will be increasing numbers of elderly individuals with a disability in the Merseyside region. Since these are typically the most vulnerable groups in terms of fire risk, there will be an increased need for fire prevention activities targeted at these groups.

\subsection{Population Behaviours and Lifestyle Trends and Fire Risk}

The next step was to assess the impact of trends in population behaviours and lifestyles associated with fire risk. Smoking rates in the UK appear to be decreasing over time [35]. Alcohol consumption rates in the UK appear to be declining for younger and middle aged individuals, but appear to be increasing for older and more affluent individuals [3]. Both smoker's materials and alcohol consumption had been previously identified as fire risk factors [23], [41], and for the period 2006-2016 in Merseyside, 51\% of fire fatalities involved smoker's materials, and $40 \%$ of fire fatalities involved alcohol consumption.

Trends in population lifestyles and behaviours can be used to estimate potential changes to fire risk levels for different population segments. This can be used to inform fire prevention approaches dealing with such behaviours and lifestyles, for example referral to smoking cessation services in the UK NHS by UK fire and rescue services.

Over the period 2006-2016 the proportions of the UK population who smoked were [35] given for Fig. 5. 
Individuals living alone in Merseyside (from UK 2011 census)
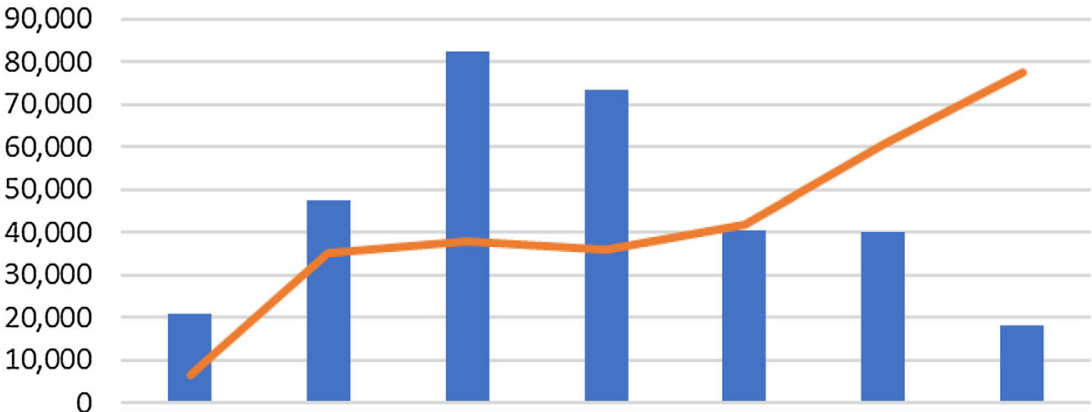

$70.00 \%$

$60.00 \%$

$50.00 \%$

$40.00 \%$

$30.00 \%$

$20.00 \%$

$10.00 \%$

Age 24 Age 25 to Age 35 to Age 50 to Age 65 to Age 75 to Age 85 $0.00 \%$ $\begin{array}{lllllll}\text { and under } & 34 & 49 & 64 & 74 & 84 & \text { and over }\end{array}$

Living alone (not living in a couple)

Percentage of age group living alone (not living in a couple)

Figure 3. The number of individuals living alone and the percentage of the given age group living alone in Merseyside from the UK 2011 Census.

Individuals in Merseyside with disability or long-term health problem (from 2011 UK Census)
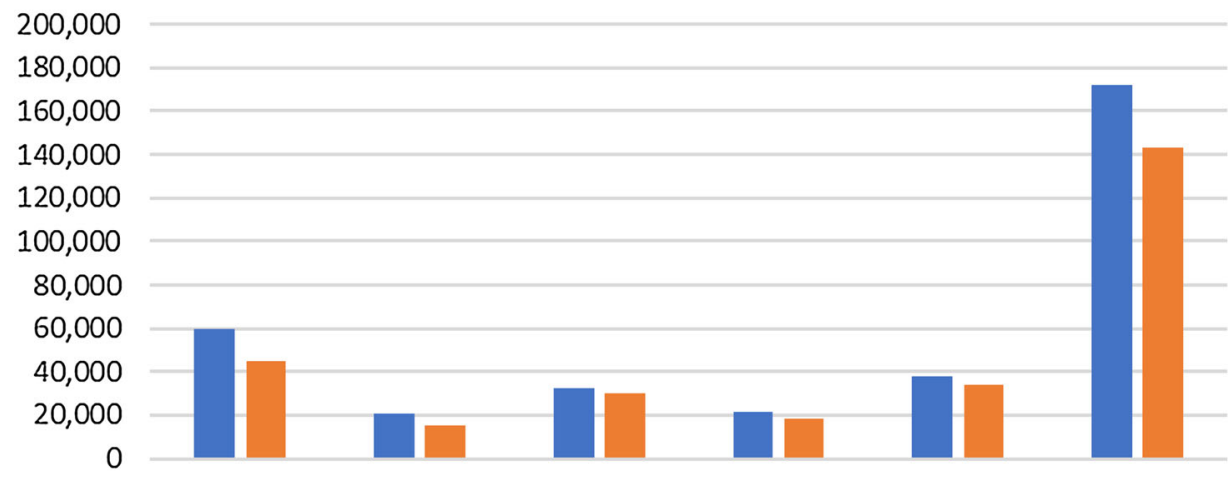

Liverpool Knowsley Sefton St. Helens Wirral Total

Day-to-day activities limited a lot Day-to-day activities limited a little

Figure 4. The number of individuals with a long-term health problem or disability in Merseyside from the UK 2011 Census.

For all the different age groups and overall, there was a significant downward trend in smoking rates (similar to reductions in smoking reported globally [42]. This downward trend would appear likely to continue, given the continuing efforts 


\section{Proportions of the UK population who smoked 2006 and 2016}

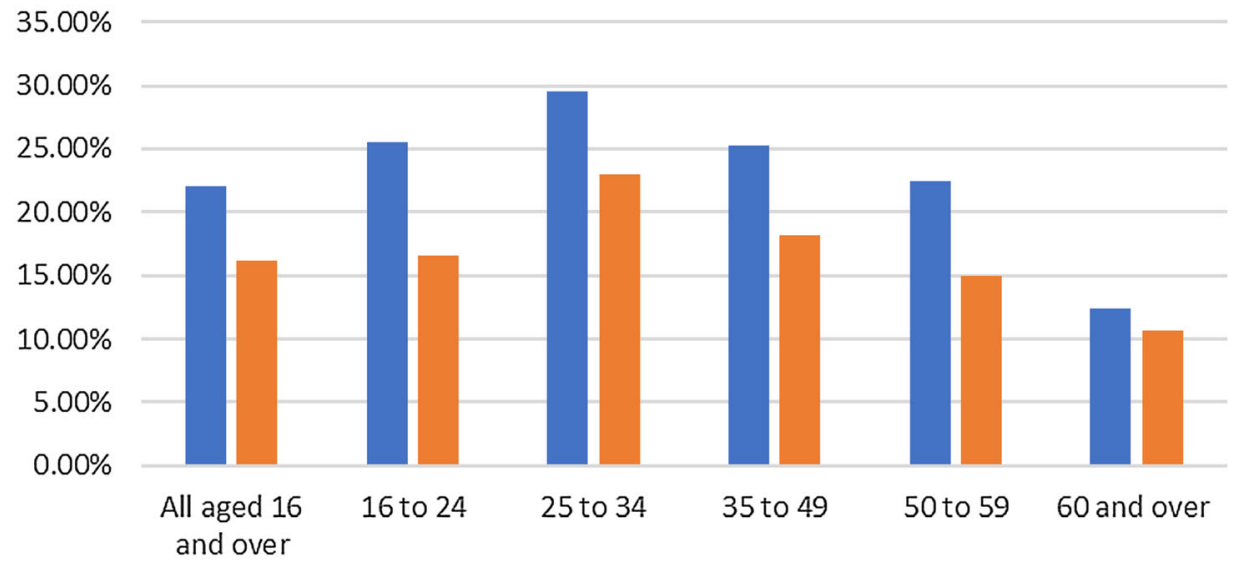

$2006 \square 2016$

\section{Figure 5. Proportions of the UK population who smoked 2006 and 2016.}

of the UK NHS in supporting smoking cessation. This would appear to indicate a slightly reducing risk of fires caused by smoking materials, even when projected population increases are considered. The decrease in smokers was greater in the age groups below 60, however, given that the proportion in the $60+$ age group had relatively increased, the relatively small decrease in smokers aged $60+$ was also significant, given the increasing numbers in that age group.

Over the period 2006-2016 the proportions of the UK population who drank more than the recommended maximum number of units of alcohol on their heaviest drinking day in the last week was [3] given for Fig. 6.

For most of the different UK age groups and overall, there was a significant downward trend in alcohol consumption, which might appear surprising compared to other countries [27]. This downward trend is possibly more of a social change in younger age groups than NHS-mediated change via alcohol awareness and alcohol management schemes. However, the age $65+$ group showed an increase in alcohol consumption during this period. In the period 2014-2016 in the UK, analysis by income indicated that the higher the level of income, the higher the level of alcohol consumption [3]. In the period 2010-2015 in Merseyside, there was a decrease in alcohol related fires from 126 in 2010/2011 to 97 in $2014 / 2015$ [10], which could indicate that reductions in alcohol consumption were having a positive impact on reducing the number of dwelling fires, however correlation does not necessarily imply causation.

- This would appear to indicate that fire prevention strategies used by UK fire and rescue services might need to increase alcohol consumption awareness by 
Individuals drinking more than recommended maximum on

heaviest day of alcohol drinking in last week in UK 2006 and 2016

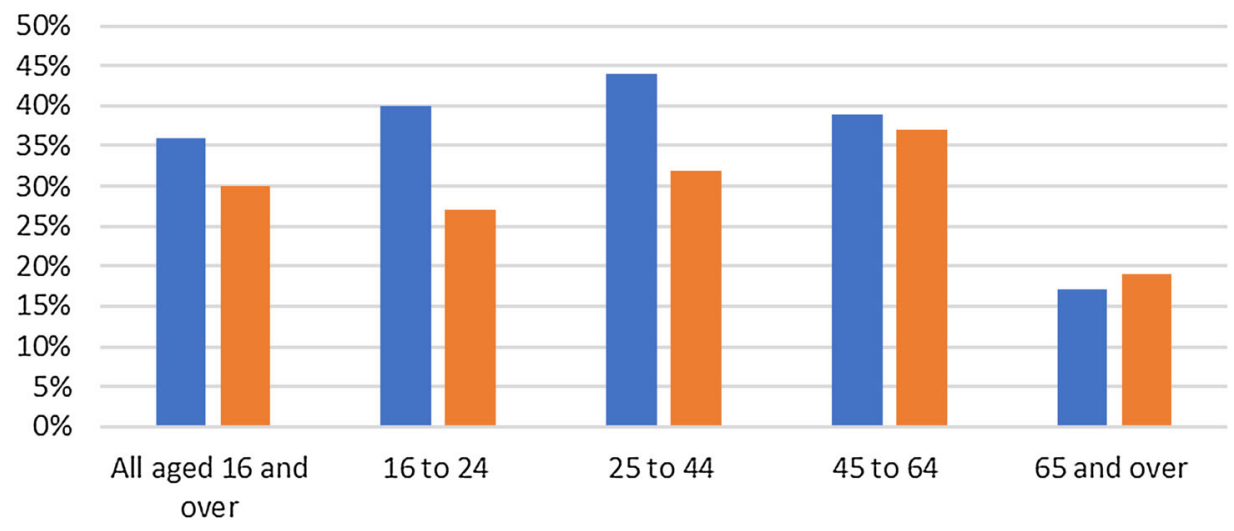

$2006 \square 2016$

\section{Figure 6. Proportions of UK population who drank more than the recommended maximum number of units of alcohol on their heaviest drinking day in the last week 2006-2016.}

elderly individuals during home fire safety checks and safe and well visits especially with regard to more affluent households.

- When discussing risk levels, it can be inappropriate to make complex assumptions regarding risk, and the layering of risks and exposures. For example, the risk level of individuals who smoke, drink excessively, and are vulnerable can be difficult to estimate, given that data is simply not available for individuals or groups across risk factors. In addition, whilst smoking is reducing there could be differences between those who have quit and those who continue, meaning that the fire risk associated with smoking may not follow a parallel trend.

\subsection{Vulnerable Group Trends and Fire Risk}

The next step involved assessment of the impact on fire risk levels of changes in health and social care provision for the most vulnerable in terms of fire risk. This group includes the disabled, and those with mental health conditions (including dementia). Fernandez-Vigil and Trueba [12] commented that mental illness such as dementia is a significant factor associated with fire risk for the elderly. In the period 2006-2016 in Merseyside, 52\% of fire fatality victims had a disability. The proportion of the UK population with dementia is increasing and by 2040, the number of people with the condition is expected to double [11]. In 2019 it was estimated that there were almost 885,000 older people with dementia in the UK and the prevalence rate of dementia among older people in the UK was $7.1 \%$ [43]. Although currently relatively small in number, increases in the number of individuals with dementia is likely to present new challenges in terms of managing 
fire prevention. The majority of people with dementia living in the UK reside in their own homes, rather than in residential care facilities [16]. There is a lack of statistics reporting the numbers of people with dementia who are injured or die in fires in the home in the UK, since Fire and Rescue Services do not collect this information as standard. However, the risk of injury or death from unintentional dwelling fires associated with dementia is likely to increase [16]. Figure 7. Shows the projected increases in the number of those aged 65 or over with dementia in the Merseyside area from 2019 to 2030 [43].

- Given the projected increases in the number of the over 65 age group with dementia, this would appear to indicate that fire risks associated with dementia are likely to increase in the near future in Merseyside, and that appropriate fire prevention approaches for this group will become more important.

\subsection{Addressing the Impact of Population Trends on Fire Risk}

In order to address the potential impact of population trends on fire risk it is important to consider likely changes concerning: the numbers and proportions of at-risk groups, behaviours and lifestyles associated with fire risk, and the circumstances of the most vulnerable groups. This can then be compared with historical fire data in order to appreciate likely changes that may occur. Figure 8 shows the number of accidental dwelling fire incidences, injuries and fatalities in the period 2006-2016 within Merseyside.

The number of accidental dwelling fires had shown a significant reduction over 2006-2016 in Merseyside, and the number of fire injuries and fire fatalities had remained low. Although the number and proportion of at-risk groups such as the elderly and the disabled and those living alone has recently increased, this did not appear to increase or even maintain the overall number of dwelling fire incidents. Given the low numbers of dwelling fire injuries and very low numbers of dwelling fire deaths per year in Merseyside, it would be difficult to draw meaningful conclusions regarding the impact of population changes on the trends in dwelling fire injuries and deaths. The number and proportion of at-risk groups in the Merseyside area appears to be predicted to increase in the coming decades, so although at present such increases have not led to an increase or even a flat trend in fire incidences, it is important that fire prevention approaches adapt in order to maintain the downward trend in fire incidences.

UK Fire and Rescue Services are currently expanding their scope of operations through the Safe and Well initiative [34] (an evolution of the Home Fire Safety Check initiative [17], which involves not only fire prevention, but also health and social care prevention initiatives such as smoking cessation, and alcohol management. Overall, the examination of the likely impact of population trends on fire risk identified the following for the Merseyside area:

- There is likely to be an increase in fire risk associated with the elderly and those with a long-term health problem or disability 
Projected increases in number of over 65 's with dementia in the Merseyside area 2019 to 2030

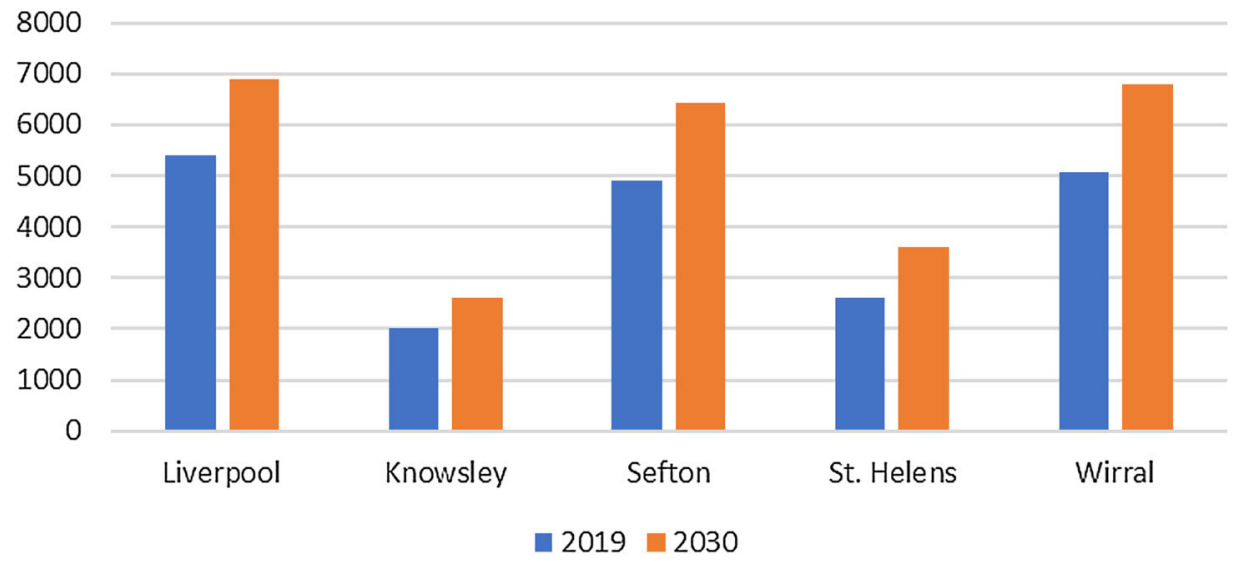

Figure 7. Projected increases in the number of those aged 65 or over with dementia in the Merseyside area from 2019 to 2030 [43].

Fire incidences, injuries and fatalities in Merseyside 2006 to 2016

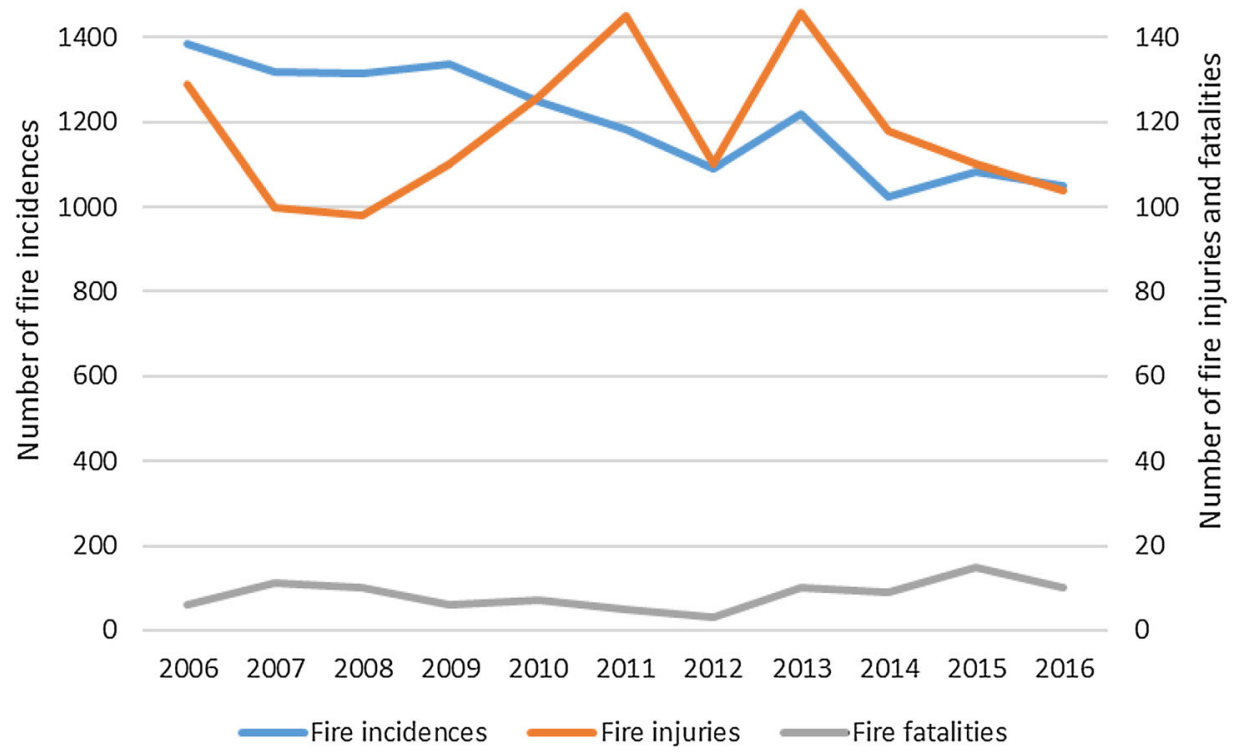

Figure 8. Accidental dwelling fire incidences, injuries and fatalities in Merseyside 2006-2016. 
- There is likely to be a decrease in fire risk associated with smoking and alcohol consumption, apart from alcohol consumption by the elderly

- There is likely to be an increase in fire risk associated with mental health and neurological conditions (particularly dementia)

Overall, this would appear to suggest that fire prevention strategies for Merseyside should increasingly target the elderly, the disabled and those with mental health and neurological conditions. The trends in fire risk for the elderly and those with those with a long-term health problem or disability have been highlighted previously. The likely increase in fire risk associated with dementia has perhaps been less highlighted, possibly due to the lack of data recorded for fire instances related to dementia. The decrease in fire risk related to alcohol consumption is perhaps more surprising, given that globally alcohol consumption rates are predicted to increase.

\subsection{Addressing Population and Life-style Trends in Fire Safety Building Codes and Public Regulations}

In addition to fire prevention activities by fire and rescue services it is also important to consider how trends in population and life-style might impact fire safety building codes and public regulations concerned with safety of life and evacuation in particular (especially as regards self-rescue and impairment). Future fire safety designs for buildings would need to better anticipate the needs of an ageing population, for example having more evacuation lifts in high-rise buildings in areas with a higher proportion of elderly residents. In addition, the fire inspection approaches adopted by fire and rescue services might need to be revised in order to consider the impact of greater numbers of elderly individuals in the different types of buildings inspected.

\section{Conclusions}

Changes in the relative proportions of different population segments, trends in population behaviours and lifestyles, and trends in health and social care for the most vulnerable in society may all impact upon fire risk. In this paper we have examined the impact of population trends upon fire risk. This has been used to assess the likely impact of population changes upon fire risk within Merseyside, and inform strategies for adapting fire prevention approaches, in terms of potential changes required to the targeting of fire prevention activities. This is required in order to appropriately address the changing nature of fire risk associated with projected population changes and trends.

The examination assessed the likely population changes in terms of age profiles, and living alone. It then assessed the likely changes in population lifestyles and behaviours associated with fire risk, such as smoking and alcohol consumption. It then assessed the likely changes in the circumstances of the most vulnerable, such as those with a disability or mental health issues. The examination finally involved analysis of how the predicted changes or historical trends in population character- 
istics were likely to affect fire risk based upon historical and current levels of fire incidences associated with the different population characteristics.

Previous research has indicated that individuals who are older, disabled or mentally handicapped are more susceptible to fatality or injury in a fire. With declining birth rates and ageing populations, there is an increased exposure of vulnerable individuals to fire risk. In this article we have proposed an approach for fire and rescue services to use the limited population data typically available (for example the detailed UK census data is only available every 10 years) to determine what future population estimates are available, and what historical population trend data are available to assist in determining what the future population of an area might be. From that it is then possible to determine, from the known groups of individuals that are vulnerable to fire risk in the area concerned, whether that group of vulnerable individuals is likely to increase, decrease or remain the same in size or proportion, which can then inform future fire prevention strategies. Although actual correlation coefficients could not be estimated between the historical (and predicted) population changes and fire incidences, injuries and fatalities, given the limitations on the data available, the research presented in this paper adds to the body of knowledge in this area by demonstrating how from a variety of sources, historical and predicted population trends can be compared to fire risks associated with known at-risk groups in order to determine how the risk associated with such groups is likely to change over time. Overall, the research undertaken indicated that fire prevention strategies for Merseyside should increasingly target the elderly, the disabled and those with mental health and neurological conditions, since these are all likely to be increasing populations with a high level of vulnerability to fire incidents. This would be relevant to other fire and rescue services worldwide that have similar population trends that could impact fire risks.

For any fire and rescue service it is important to understand how future population changes may impact fire risk. In this paper this has been addressed via a systematic approach that could be used by any fire and rescue service to analyze the fire risks associated with different population segments, analyze trends in population lifestyles and behaviors associated with fire risk, analyze population trends in vulnerable groups, analyze the nature of the population trends, and the impact that such trends may have on the levels of fire risk for different groups in the community.

It is important, when discussing risk levels, to be careful not to make complex assumptions regarding risk, and the nature of the layering of risks and exposures. For example, the risk level of individuals who smoke, drink excessively, and are vulnerable can be difficult to estimate, given that data is simply not available for individuals or groups across risk factors. In addition, whilst smoking and alcohol consumption is reducing there could be differences between those who have quit smoking and reduced alcohol consumption and those who continue, meaning that the fire risks associated with smoking and alcohol consumption may not follow parallel trends. 
The originality of the research reported in this paper is the detailed examination of the likely impact of population trends upon fire risk within an area. This research can be applied in the UK and elsewhere by examining similar trends in population group changes, lifestyle and behaviour changes, and changes in the circumstances of the most vulnerable groups. Different trends may be applicable to other countries, for example in countries with a higher incidence of wildfires than the UK. Future work would be useful to compare the findings of this research to other regions, or countries, and to consider future trends such as the impact of drugs with regard to fire risk in different regions and countries.

\section{Open Access}

This article is licensed under a Creative Commons Attribution-NonCommercial 4.0 International License, which permits any non-commercial use, sharing, adaptation, distribution and reproduction in any medium or format, as long as you give appropriate credit to the original author(s) and the source, provide a link to the Creative Commons licence, and indicate if changes were made. The images or other third party material in this article are included in the article's Creative Commons licence, unless indicated otherwise in a credit line to the material. If material is not included in the article's Creative Commons licence and your intended use is not permitted by statutory regulation or exceeds the permitted use, you will need to obtain permission directly from the copyright holder. To view a copy of this licence, visit http://creativecommons.org/licenses/by-nc/4.0/.

\section{Appendix}

See Fig. 9

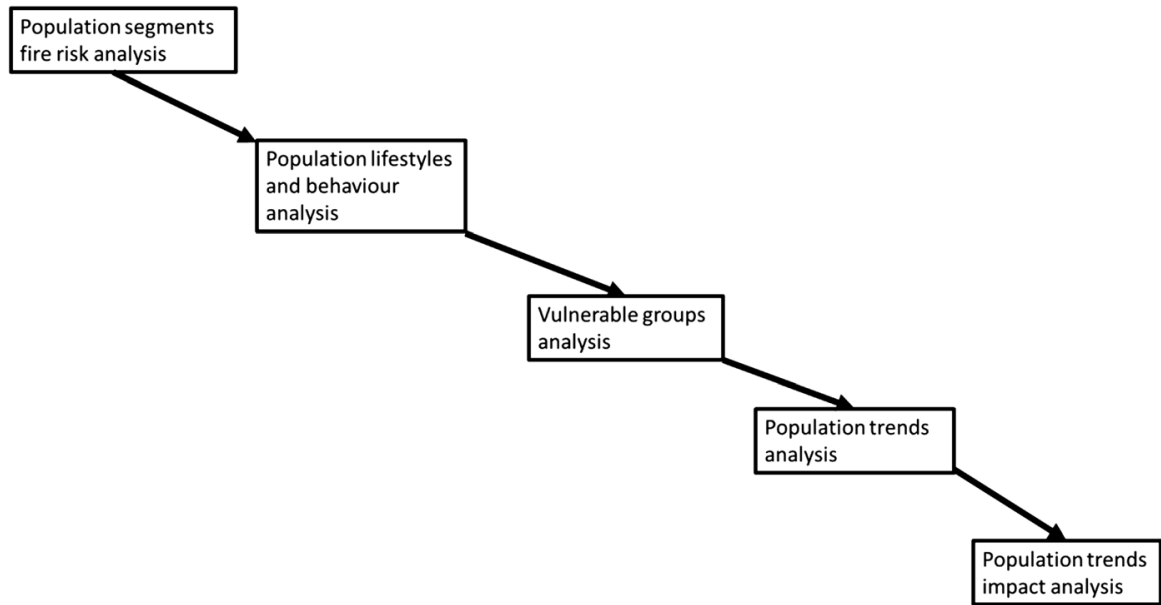




\section{References}

1. Addai E, Tulashie S, Annan J, Yeboah I (2016) Trend of fire outbreaks in Ghana and ways to prevent these incidents. Saf Health Work 7(4):284-292

2. AE (2020) age platform Europe, ageing Europe - looking at the lives of older people in the EU, https://www.age-platform.eu/publications/ageing-europe-looking-lives-older-peo ple-eu-eurostat-2019-report

3. Alcohol (2017) UK ONS adult drinking habits in great britain: 2005 to $2016 \mathrm{https}: / / \mathrm{ww}$ w.ons.gov.uk/peoplepopulationandcommunity/healthandsocialcare/drugusealcoholands moking/bulletins/opinionsandlifestylesurveyadultdrinkinghabitsingreatbritain/2005t o2016

4. Breslin D, Dobson S, Smith N (2019) Improving the effectiveness of fire prevention using the "premonition" agent-based model of domestic fire risk behaviours. Int J EmergServ 8(3):280-291

5. Cassidy P, McConnell N, Boyce K (2020) The older adult: associated fire risks and current challenges for the development of future fire safety intervention strategies. Fire Mater . https://doi.org/10.1002/fam.2823

6. Chainey S (2013) Using the vulnerable localities index to identify priority areas for targeting fire safety services. Fire Saf J 62:30-36

7. Chien $\mathrm{S}, \mathrm{Wu} \mathrm{G}(2008)$ The strategies of fire prevention on residential fire in Taipei. Fire Saf J 43:71-76

8. Corcoran J, Higgs G, Anderson T (2013) Examining the use of a geodemographic classification in an exploratory analysis of variations in fire incidence in South Wales, UK. Fire Saf J 62:37-48

9. Dean E, Taylor M, Francis H, Clark A (2016) An exploration of community and culture related fire injury risks, UKAIS conference. Oxford University, Oxford

10. Dean E, Taylor M, Francis H, Appleton D, Jones M (2018) An exploration of alcohol related fire incidences. J Risk Res 21(10):1217-1232

11. Dementia (2017) UK NHS Dementia statistics https://www.england.nhs.uk/statistics/20 17/10/04/dementia-assessment-and-referral-data-collection-july-2017/

12. Fernández-Vigil M, Trueba B (2019) Elderly at home: a case for the systematic collection and analysis of fire statistics in Spain. Fire Technol 55(6):2215-2244

13. Gilbert S, Butry D (2018) Identifying vulnerable populations to death and injuries from residential fires. InjPrev 24(5):358-364

14. Guzman-Castillo M, Ahmadi-Abhari S, Bandosz P, Capewell S, Steptoe A, Singh-Manoux A, Kivimaki M, Shipley M, Brunner E, O'Flaherty M (2017) Forecasted trends in disability and life expectancy in England and Wales up to 2025: a modelling study. Lancet 2:307-313

15. NFCC (2017) Independent review of building regulations and fire safety. National Fire Chiefs Council, Tamworth

16. Heward M, Kelly F (2018) Research and education to understand fire risks associated with dementia: a collaborative case study (innovative practice). Dementia . https:// doi.org/10.1177/1471301218790850

17. HFSC (2018) Home fire safety check https://www.merseyfire.gov.uk/aspx/pages/prevent ion/campaign.aspx

18. Higgins E, Taylor M, Jones M, Lisboa P (2013) Understanding community fire risk-a spatial model for targeting fire prevention activities. Fire Saf J 62:20-29

19. Higgins E, Taylor M, Francis H, Jones M, Appleton D (2014) The evolution of geographical information systems for fire prevention support. Fire Saf J 69:117-125 
20. Higgins E, Taylor M, Francis H, Jones M, Appleton D (2015) Transforming fire prevention: a case study. Transform Gov Policy Process People 9(2):223-236

21. Kegler S, Dellinger A, Ballesteros M, Tsai J (2018) Decreasing residential fire death rates with the prevalence of adult cigarette smoking - United States, 1999-2015. J Saf Res 67:197-201

22. Kose S (1999) Emergence of aged populace: who is at higher risk in fires?. Fire Mater 23(6):337-340

23. Leth P, Gregersen M, Sabroe S (1998) Fatal residential fire accidents in the municipality of copenhagen, 1991-1996. Prev Med 27:444-451

24. Li F, Zhu Q, Zhuang J (2018) Analysis of fire protection efficiency in the United States: a two-stage DEA-based approach. OR Spectr 40(1):23-68

25. Livingston G, Sommerlad A, Orgeta V, Costafreda S, Huntley J, Ames D, Ballard C, Banerjee S, Burns A, Cohen-Mansfield J, Cooper C, Fox N, Gitlin L, Howard R, Kales H, Larson E, Ritchie K, Rockwood K, Sampson E, Samus Q, Schneider L, Selbæk G, Teri L, Mukadam N (2017) Dementia prevention, intervention, and care. Lancet 390:2673-2734

26. Lowton K, Laybourne A, Whiting D, Martin F (2010) Can fire and rescue services and the national health service work together to improve the safety and wellbeing of vulnerable older people? Design of a proof of concept study. BMC Health Serv Res 10(1):327-336

27. Manthey J, Shield K, Rylett M, Hasan O, Probst C, Rehm J (2019) Global alcohol exposure between 1990 and 2017 and forecasts until 2030: a modelling study. The Lancet 393(10190):2493-2502

28. Miller M (2012) Impact of emerging social change and technological developments on fire service operations, New Zealand fire service commission research report number 121, Wellington, New Zealand, ISBN 978-1-877539-64-0

29. MOSAIC (2018) Mosaic UK consumer and demographic data, experian http://www.ex perian.co.uk/marketing-services/products/mosaic-uk.html

30. NHS Digital (2017) NHS digital statistics https://digital.nhs.uk/

31. Nomis (2018) Nomis, official labour market statistics, UK office for national statistics, https://www.nomisweb.co.uk/

32. ONS (2017) Subnational population projections for England: 2014-based projections ht tps://www.ons.gov.uk/peoplepopulationandcommunity/populationandmigration/populat ionprojections/bulletins/subnationalpopulationprojectionsforengland/2014basedprojectio ns

33. ONS (2019) The cost of living alone https://www.ons.gov.uk/peoplepopulationandcom munity/birthsdeathsandmarriages/families/articles/thecostoflivingalone/2019-04-04

34. SAFE (2017) Fire safety in the home, safe and well visit http://www.fireservice.co.uk/sa fety/

35. Smoking (2016) UK ONS Adult smoking habits in the UK: 2016 https://www.ons.gov. uk/peoplepopulationandcommunity/healthandsocialcare/healthandlifeexpectancies/bullet ins/adultsmokinghabitsingreatbritain/2016

36. Taylor M, Higgins E, Francis M, Lisboa P (2011) Managing unintentional dwelling fire risk. J Risk Res 14(10):1207-1218

37. Taylor M, Lisboa P, Kwasnica V, Higgins E (2012) An exploration of causal factors in unintentional dwelling fires. Risk Manage 14:109-125

38. Taylor M, Higgins E, Lisboa P, Jarman I, Hussain A (2016) Community fire prevention via population segmentation modelling. Community Dev J 51(2):229-247

39. Taylor M, Appleton D, Keen G, Fielding J (2019) Assessing the effectiveness of fire prevention strategies. Public Money Manage 39(6):418-427 
40. Turner S, Johnson R, Weightman L, Rodgers S, Arthur G, Bailey R, Lyons R (2017) Risk factors associated with unintentional house fire incidents, injuries and deaths in high-income countries: a systematic review. InjPrev 23:131-137

41. Waterhouse K (2010) A review of fire-related deaths in Alberta. Can Soc Forensic Sci J 43(4):171-180

42. WHO (2020) World Health Organisation, WHO global report on trends in tobacco smoking 2000-2025 https://www.who.int/tobacco/publications/surveillance/reportontren dstobaccosmoking/en/

43. Wittenberg R, Hu B, Barraza-Araiza L, Rehill A (2019) Projections of older people with dementia and costs of dementia care in the United Kingdom, 2019-2040. Care Policy and Evaluation Centre, London School of Economics and Political Science, London

44. Wuschke K, Clare J, Garis L (2013) Temporal and geographic clustering of residential structure fires: a theoretical platform for targeted fire prevention. Fire Saf J 62:3-12

45. Zhang X, Yao J, Sila-Nowicka K (2018) Exploring spatiotemporal dynamics of urban Fires: a case of nanjing China. ISPRS Int J Geo-Information 7(1):7

Publisher's Note Springer Nature remains neutral with regard to jurisdictional claims in published maps and institutional affiliations. 